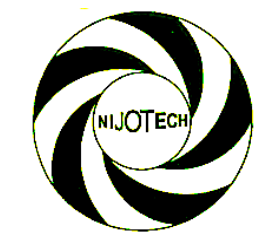

Nigerian Journal of Technology (NIJOTECH)

Vol. 39, No. 2, April 2020, pp. 417 - 423

Copyright@ Faculty of Engineering, University of Nigeria, Nsukka

Print ISSN: 0331-8443, Electronic ISSN: 2467-8821

www.nijotech.com

http://dx.doi.org/10.4314/nit.v39i2.11

\title{
PERFORMANCE AND BEHAVIOR OF A HORIZONTAL WELL IN RESERVOIR SUBJECT TO DOUBLE-EDGED WATER DRIVE
}

\author{
J. O. Oloro ${ }^{1, *}$ and S.E. Adewole ${ }^{2}$ \\ 1, Chemical and Petroleum Engineering Dept, Delta State Univ., Oleh Campus, Delta State, Nigeria \\ 2, Petroleum Engineering Department, University of Benin, Benin City, Edo State, NigeriA \\ E-mail addresses: 1 olorojo@delsu.edu.ng, 2 steve.adewole@uniben.edu
}

\begin{abstract}
Determining the performance and behavior of horizontal well subjected by double-edge water drive reservoir at a late time period has been a concern to many researchers. Wellbore pressure losses during production in horizontal well increase conning propensity at late period thus rendering some part of the horizontal well unproductive. This restricts the effectiveness of increasing the horizontal well length due to wellbore pressure losses along the horizontal well. This study was carried out by using source function and Newman rule to develop models to predict the performance and behavior of a horizontal well which was subjected by double Edgewater and numerical method was used for the computation and Sensitivity analysis of parameters was performed. The results show that the performance and behavior of the reservoir for this study were found to be when the well is position at well length (XwD: $\left.Y_{w D}:{ }_{w D}\right)$, in the ratio of 12:7:15 respectively.
\end{abstract}

Keywords: Double edged, Performance, Reservoir, Water Drive, Late Period.

\section{INTRODUCTION}

Performance of horizontal wells for various reservoir and production conditions has been studied widely in recent years. Subjects such as critical production rates, time for the cone to break-through, and production after break-through have been studied with physical, analogue, analytical and numerical simulation models. Researchers have also studied the interface movement through experimental and numerical techniques and thus tried to predict the coning behavior of the oil reservoirs. Productivity and pressure behavior of horizontal wells under various reservoir conditions have been extensively[1-5]. Due to the low pressure-drawdown around the wellbore in the case of horizontal wells as compared to vertical wells, a high production rate is expected without serious coning. In this regard, various methods to calculate critical rate, breakthrough time and WOR for horizontal wells with bottom-water drive can be found in the literature [6-10]. Analytical work on break-through time for a horizontal well placed in a reservoir with either bottom-water drive, or gas-cap drive, or both, has also been presented [11].Water and gas coning is a major issue in petroleum engineering. In the case of horizontal wells, this problem is significantly reduced because of the longer exposed wellbores and lesser pressure drawdown between the reservoir and the well bore. For horizontal wells, coning is referred to as cresting' for water and 'cusping' for gas. An extensive review of the work conducted on the coning problem has been recently. published

It is evident that major contributions have been made to predict the productivity, simulate the fluid flow, evaluate the critical rate and breakthrough time, and predict the cone shape and the interface movement. However, most of the research has been done to study the performance of horizontal wells theoretically and numerically. There are a lot of research achievements on pressure distribution of horizontal well in the bottom water reservoir, but fewer in edge water [12-16], no study has been conducted to investigate the performance of horizontal well in reservoir subjected with double Edgewater drive at late time.

* Corresponding author, tel: +234 8052756328 


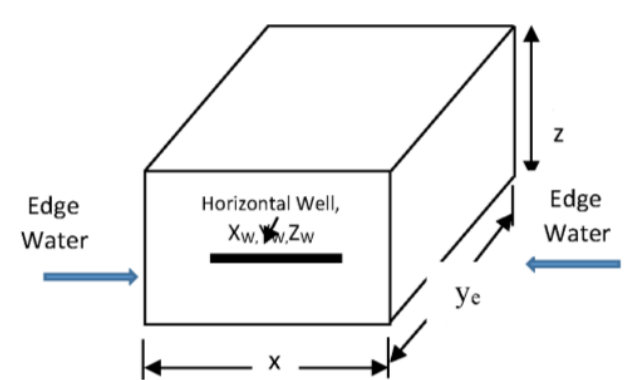

Figure 1: Double Edgewater drive Reservoir

This water may come from both sides of axes as revealed in figure 1.Thus, there is a need to investigate the performance and behavior of horizontal wells under such a drive mechanism. The present research was directed towards this need.

\subsection{Description of Model}

Figure 1 shows the complete bounded reservoir subjected by two edge water. The reservoir has length $x_{e}$ in the $x$-direction, length $y_{e}$ in $y$-direction and length $z_{e}$ in the $z$-direction. It has a horizontal well locations $x_{w}, y_{w}$ and $z_{w}$ in $x, y$ and $z$ directions respectively [17].

The source functions are selected from basic instantaneous source functions table for $x, y$ and $z$ axis's given as $\mathrm{ix}(\mathrm{x}), \mathrm{i}(\mathrm{y}), \mathrm{v}(\mathrm{z})$. Equation 1,2 and 3 are the source functions for the three axes in dimensionless form.

\section{METHODOLOGY}

The following steps are taken in deriving each of the models [18]

1. Chose a boundary condition for each axis.

2. Select the appropriate source function for each axis

3. Apply Newman product rule to arrive at the pressure expression.

4. Compute the pressure and pressure derivative for a given period.

From the physical model in Figure 1 , at the $x$-axis, well experiences an infinite slab source from an infinite slab reservoir in which the top is a constantpressure boundary [19]. Hence, the appropriate source function is given in equation 1 .

$$
=\frac{4}{\pi} \sum_{l=1}^{\infty} \exp \left(-\frac{l^{2} \pi^{2} t_{D}}{x_{e D}^{2}}\right) \sin \left(\frac{l \pi}{x_{e D}}\right) \sin \left(\frac{l \pi x_{w D}}{x_{e D}}\right) \sin \left(\frac{l \pi x_{D}}{x_{e D}}\right)
$$

Along the $y$-axis, the well is assumed to be experiencing sealed boundaries at both ends. It is, therefore, an infinite plane source in an infinite slab reservoir at an early time, represented as follows:

$s\left(y_{D}, t_{D}\right)=\frac{1}{y_{e D}}[1+$

$\left.2 \sum_{m=1}^{\infty} \exp \left(-\frac{m^{2} \pi^{2} t_{D}}{y_{e D}^{2}}\right) \cos \left(\frac{m \pi y_{w D}}{y_{e D}}\right) \cos \left(\frac{m \pi y_{D}}{y_{e D}}\right)\right]$

Along the z-axis, the well experiences an infinite plane source in an infinite slab reservoir represented as follows:

$$
\begin{aligned}
& s\left(z_{D}, t_{D}\right)=\frac{1}{h_{D}}[1+ \\
& \left.2 \sum_{n=1}^{\infty} \exp \left(-\frac{n^{2} \pi^{2} t_{D}}{h_{D}^{2}}\right) \cos \left(\frac{n \pi z_{w D}}{h_{D}}\right) \cos \left(\frac{n \pi z_{D}}{h_{D}}\right)\right]
\end{aligned}
$$

\subsection{Model for Pressure Distribution of Completely Bounded Reservoir}

Using the Newman product rule, the dimensionless pressure distribution is

$$
P_{D}=2 \pi h_{D} \int_{0}^{t_{D}} S\left(x_{D}, t_{D}\right) S\left(y_{D}, t_{D}\right) S\left(z_{D}, \tau\right) \partial t_{D}
$$

Putting equations 1,2 and 3 in 4 we have $p_{D}=$

$8 \int_{0}^{t_{D}} \sum_{l=1}^{\infty} \exp \left(-\frac{l^{2} \pi^{2} t_{D}}{x_{e D}^{2}}\right) \sin \left(\frac{l \pi}{x_{e D}}\right) \sin \left(\frac{l \pi x_{w D}}{x_{e D}}\right) \sin \left(\frac{l \pi x_{D}}{x_{e D}}\right) \times$ $\frac{1}{y_{e D}}[1+$

$\left.2 \sum_{m=1}^{\infty} \exp \left(-\frac{m^{2} \pi^{2} t_{D}}{y_{e D}^{2}}\right) \cos \left(\frac{m \pi y_{w D}}{y_{e D}}\right) \cos \left(\frac{m \pi y_{D}}{y_{e D}}\right)\right] \times[1+$ $\left.2 \sum_{n=1}^{\infty} \exp \left(-\frac{n^{2} \pi^{2} t_{D}}{h_{D}^{2}}\right) \cos \left(\frac{n \pi z_{w D}}{h_{D}}\right) \cos \left(\frac{n \pi z_{D}}{h_{D}}\right)\right] d \tau(5)$

Equation 5 is the pressure distribution for a reservoir with two edge water external boundaries.

The dimensionless pressure derivative is derived as $p_{D}^{\prime}=t_{D} \frac{\partial p_{D}}{\partial t_{D}}$

Using Equation 5, Equation 6 is derived as $p_{D}^{\prime}=$

$$
\begin{aligned}
& 8 t_{D} \sum_{l=1}^{\infty} \exp \left(-\frac{l^{2} \pi^{2} t_{D}}{x_{e D}^{2}}\right) \sin \left(\frac{l \pi}{x_{e D}}\right) \sin \left(\frac{l \pi x_{w D}}{x_{e D}}\right) \sin \left(\frac{l \pi x_{D}}{x_{e D}}\right) \times \\
& \frac{1}{y_{e D}}\left[1+2 \sum_{m=1}^{\infty} \exp \left(-\frac{m^{2} \pi^{2} t_{D}}{y_{e D}^{2}}\right) \cos \left(\frac{m \pi y_{w D}}{y_{e D}}\right) \cos \left(\frac{m \pi y_{D}}{y_{e D}}\right)\right] \times \\
& \left.\left[1+2 \sum_{n=1}^{\infty} \exp \left(-\frac{n^{2} \pi^{2} t_{D}}{h_{D}^{2}}\right) \cos \left(\frac{n \pi z_{w D}}{h_{D}}\right) \cos \left(\frac{n \pi z_{D}}{h_{D}}\right)\right]\right)
\end{aligned}
$$

\section{RESULTS AND DISCUSSION}

Numerically, equation 6 is solved using GaussLegendre quadrature, since only the last flow period is considered. The dimensionless pressure derivative, $P_{D}{ }^{1}$ is computed by direct substitution. Several reservoirs, fluid and wellbore parameters are now selected and substituted after the numerical integration. Results obtained for the several parameters considered are shown in Table 1 through to Table 4.The performance and behavior of each reservoir are presented in each of the Tables. At an 
early time, the aquifer at each edge of the reservoir considered where very active and became very sensitive to fluid withdrawer with time as we have seen from the Tables. The pressure became stable as from $t_{D}>10$ which is an indication that boundary has been encountered. The pressure derivative gives a true picture of what happens as oil is produced from the reservoir and all became zero at $t_{D}=100$. As the oil is produced there is a decline in pressure, but with the help of the water edge at both edge of the reservoir, the pressure is buildup. Figure 2 to Figure 5 illustrates the performance and behavior of a reservoir subjected by double edge water at late time. This is a period refer to Pseudo-steady state and this started when the pressure disturbance created by the producing well is felt at the boundary of the well drainage area.

From Figure 4 it is obvious that the dimensionless height has no effect on pressure derivative, which means that the thickness of the reservoir does not affect oil production. Hence a well position at any height in the reservoir does not affect much on the quantity of the oil production for the oil reservoir.

The effect of well position in the z-direction on $P_{D}$ is shown in figure 5 . From the figure, at the early time during well production, there was just a little effect, but time ( $t_{D} \geq 100$ ) there was no significant change in well production. Hence the well can be position at any point in the z-direction. This can also be seen in figure 6 , which illustrates the effect of position of a well in the z-direction on dimensionless pressure derivative, $\mathrm{P}_{\mathrm{D}}{ }^{1}$.

Figure 7 shows the effect of dimensionless well position in y-direction on dimensionless pressure derivative. From the figure, one can say that there no significant change or effect on well production as from $t_{D} \geq 10$. Hence the well can be position at any point in the $y$-direction between 0.74 and 1.48
Figure 8 illustrates the effect of dimensionless well position in $\mathrm{x}$-direction on dimensionless pressure derivative. From the figure, it is obvious that the well can be position at any point between $1 \geq \mathrm{x}_{\mathrm{wD}} \geq 0.50$ for higher performances.

The effect of dimensionless well position in the $x$ direction on $P_{D}$ is shown in figure 9.From the figure one can see that with time during production, the effect of well position in $\mathrm{x}$-direction becomes insignificant.

Table 1: Dimensionless pressure and Dimensionless Derivative at $X_{e D}=5$

\begin{tabular}{lll}
\hline$t_{D}$ & $P_{D}$ & $P_{D}^{1}$ \\
\hline 0.001 & 15.99998 & 0.00478 \\
$1.00 \mathrm{E}-02$ & $1.60 \mathrm{E}+01$ & 0.03888 \\
0.1 & 16.00001 & 0.18393 \\
1 & 16 & 1.2495 \\
10 & 16 & 0.357 \\
100 & 16 & $1.29 \mathrm{E} 15$ \\
1000 & 16 & $4.80 \mathrm{E}-169$ \\
10000 & 16 & 0 \\
\hline
\end{tabular}

Table 2: Dimensionless Pressure and Dimensionless Derivative at $X_{e D}=3$

\begin{tabular}{lll}
\hline$t_{D}$ & $\mathrm{PD}_{\mathrm{D}}$ & $\mathrm{PD}^{1}$ \\
\hline 0.001 & 20.65303 & $3.78 \mathrm{E}-03$ \\
$1.00 \mathrm{E}-02$ & $2.06 \mathrm{E}+01$ & $3.62 \mathrm{E}-02$ \\
0.1 & 18.97106 & 0.254177 \\
1 & 16.448948 & 0.448948 \\
10 & 16.00002 & 0.000205 \\
100 & 16 & $2.61 \mathrm{E}-46$ \\
1000 & 16 & 0 \\
10000 & 16 & 0 \\
\hline
\end{tabular}




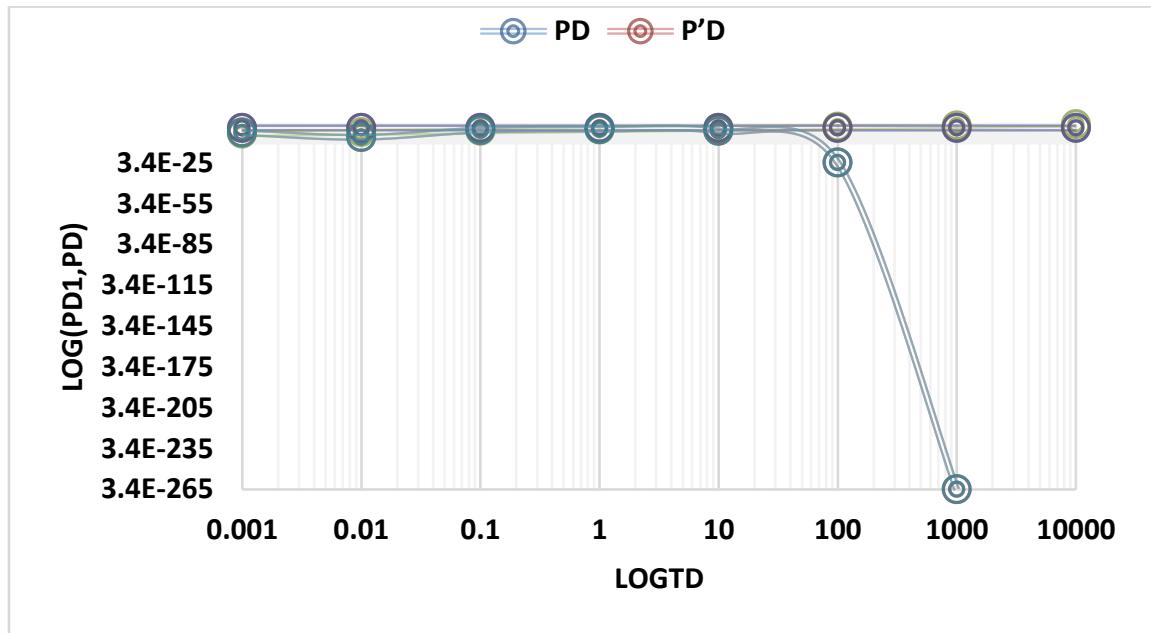

Figure 2: Dimensionless Pressure and Dimensionless Derivative Responses at $X_{e D}=4$

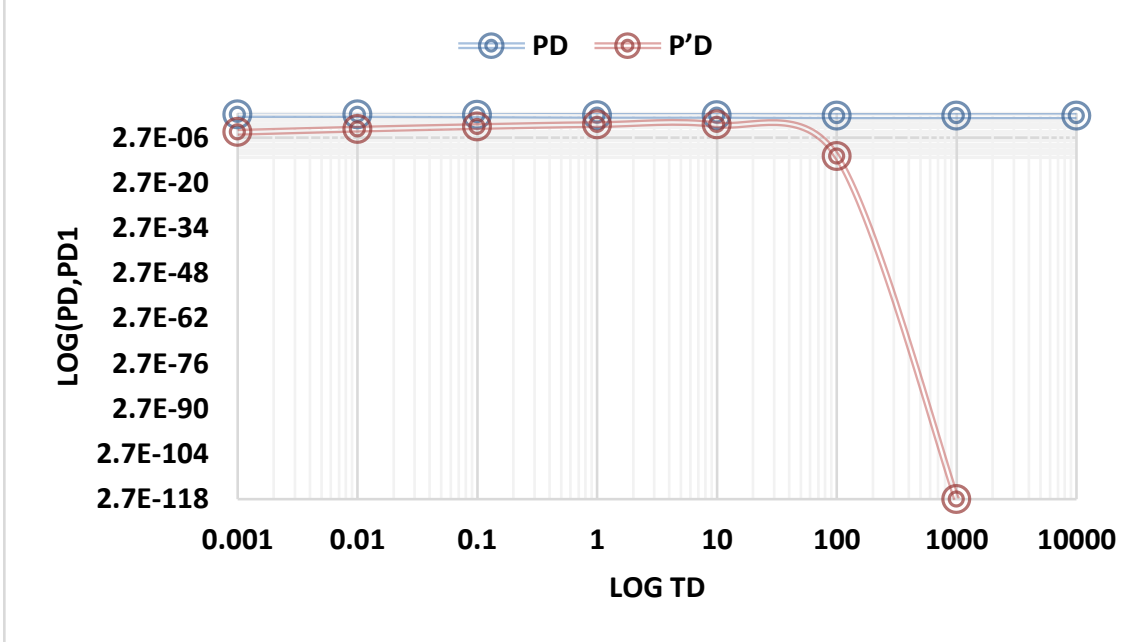

Figure 3: Dimensionless Pressure and Dimensionless Derivative Responses at $X_{e D}=6$

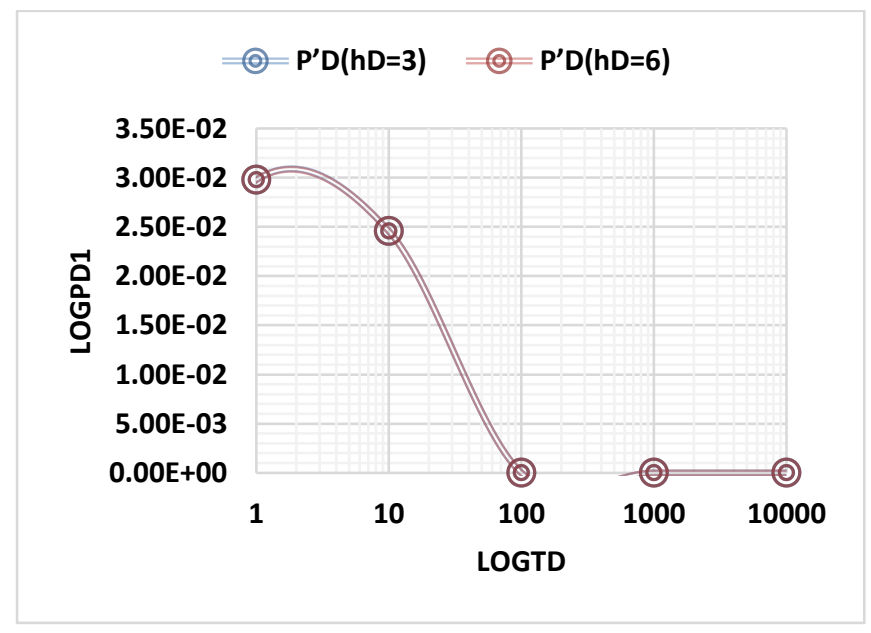

Figure 4: Effect of dimensionless height on $P_{D}{ }^{1}$

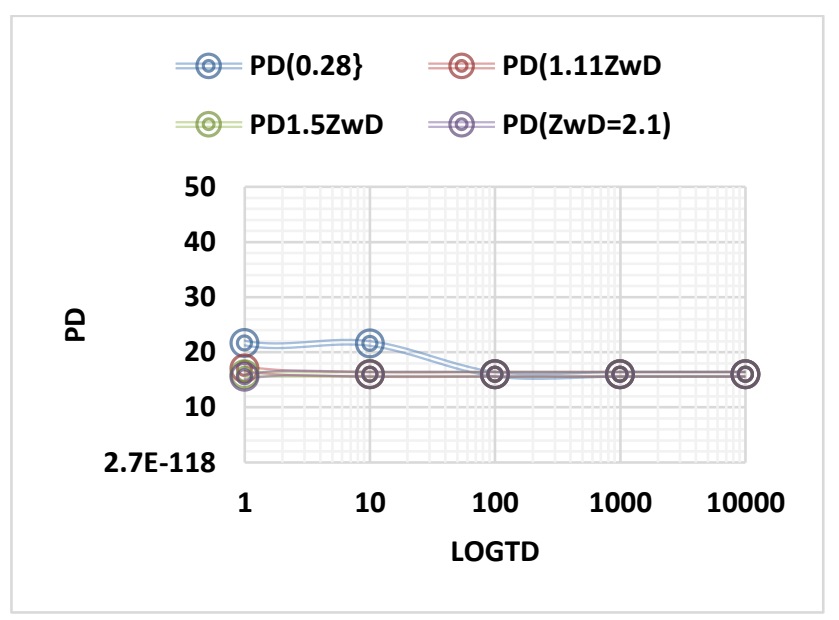

Figure 5: Effect of dimensionless well position in the $z$-direction on $P_{D}$ 


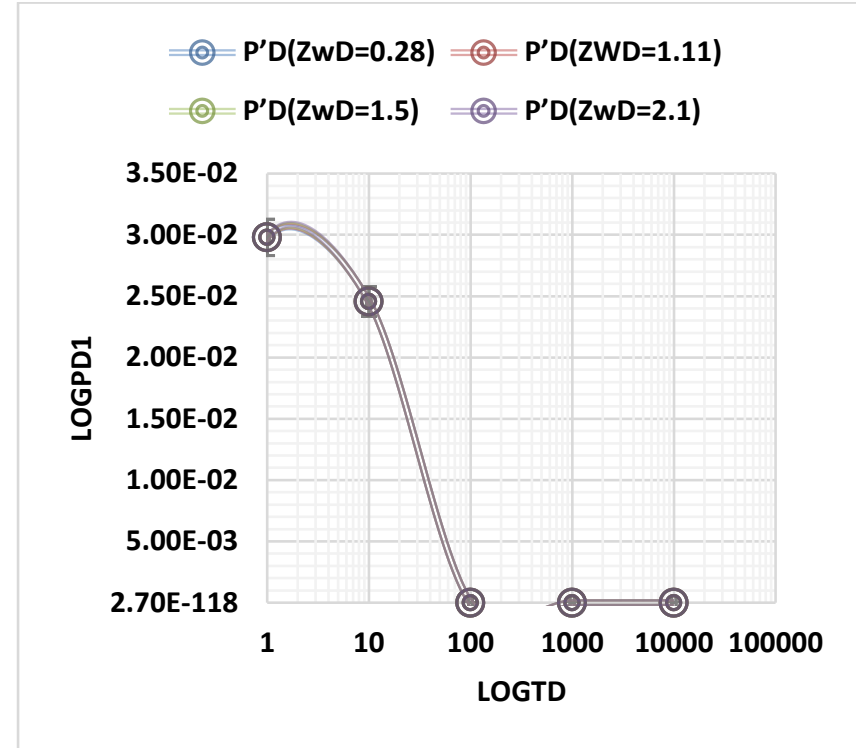

Figure 6: Effect of dimensionless well position in the $z$-direction on $P_{D}{ }^{1}$

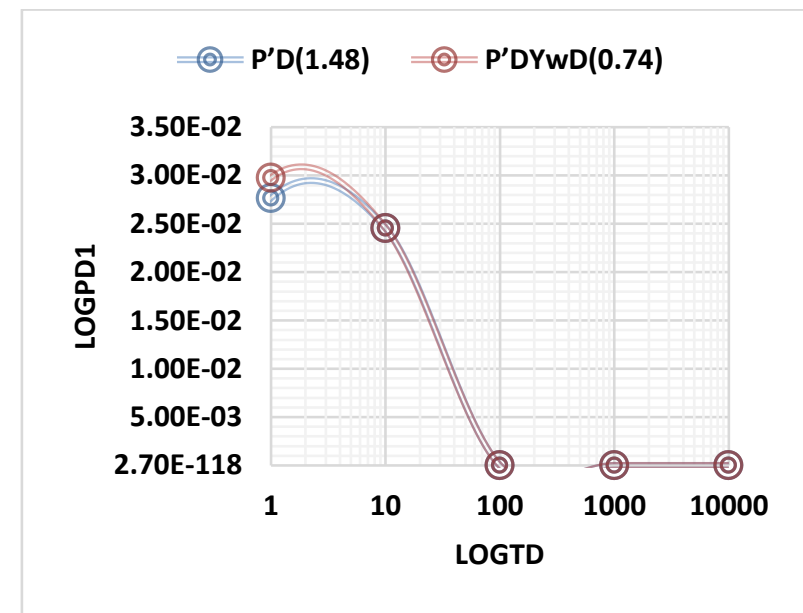

Figure 7: Effect of dimensionless well position in $y$ direction on $P_{D}{ }^{1}$

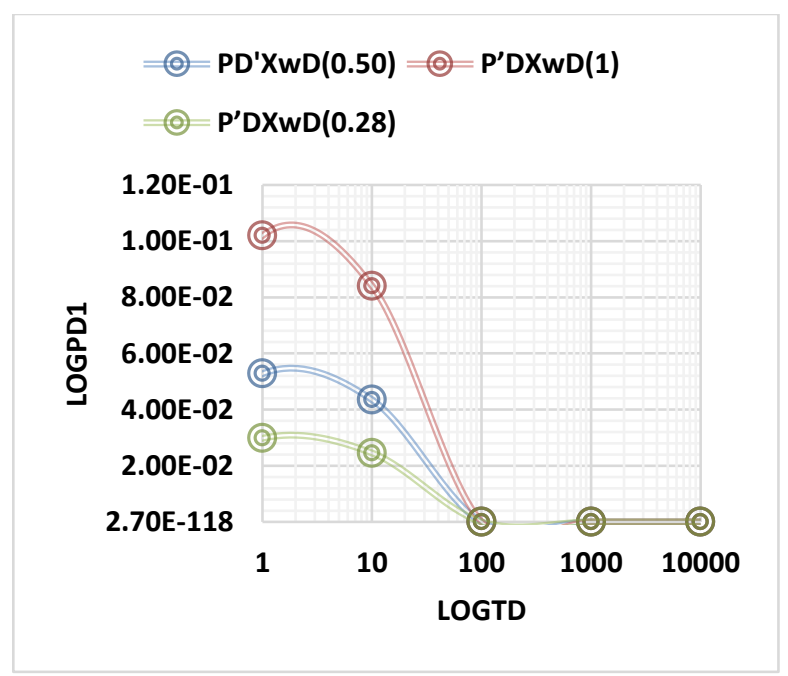

Figure 8: Effect of dimensionless well position in $x$ direction on $P_{D}{ }^{1}$

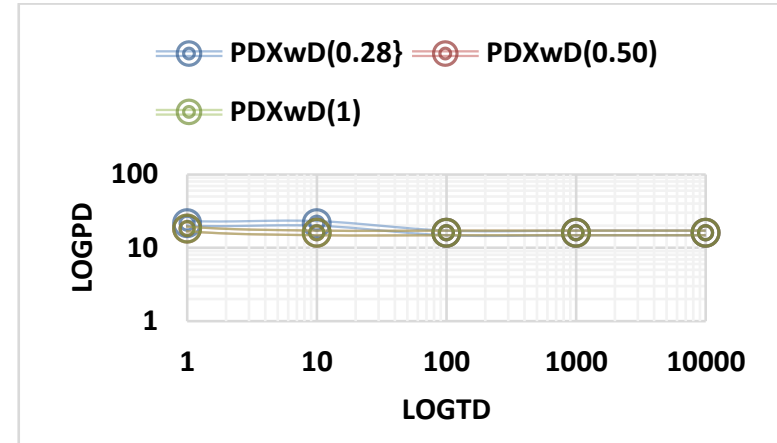

Figure 9 :Effect of dimensionless well position in the $x$-direction on $P_{D}$

It is a usual thing when talking about edge-water and bottom-water while discussing water encroachment into a reservoir. Bottom-water take place directly beneath the oil zone while edge-water occurs off the flanks of the structure at the edge of the oil zone and double edge is at the two edges of the oil zone Thus, the prediction of reservoir performance and behavior usually requires accurate models [20-21] and these Models are given as equations 5 and 7 which is the major objective for this study. With these two models developed, prediction of reservoir performance and behavior of a horizontal well subjected by a double Edgewater drive was achieved and the results are presented above.

The data in Table 1 has a decline rate of $1.43 \mathrm{e}-18$. The decline started at $t_{D}=100$ and the fluid encounter boundary at $t_{D}=0.001$ and with $P_{D}$ equal to 16. Figure 2 has a decline rate of $7.48 \mathrm{e}-28$. The decline started at $t_{D}=98$ and the fluid encounter boundary at $t_{D}=0.001$ and with $P_{D}$ equal to 16 . The date in Table 2 has a decline rate of $2.90 \mathrm{e}-49$. The decline started at $t_{D}=6$ and the fluid encounter boundary at $t_{D}=1000$ and with $P_{D}$ equal to 20.65. The data in Table 4 has a decline rate of $5.16 \mathrm{e}-15$. The decline started at $t_{D}=60$ and the fluid encounter boundary at $t_{D}=100$ and with $P_{D}$ equal to 38.39.

Tables 1 and Table 2, shows the performance and behavior of a Reservoir subjected by two Edgewater drive. The pressure became stable with time while the pressure derivative decreases to zero with time, in other words, there was water production at the initial time but with time the well started to produce oil. This production started to increase but this became stable as a result of the boundary effect as shown in Figure 2 and Figure 3.

Pressure derivative graphs give a picture of when the fluid in the reservoir encounter boundary. The 
results in Figure 3 show that aquifer is active and more sensitive when compared to others. Hence it gives the best oil production for a long time before the boundary effect experienced and also the amount of oil produced was the highest as seen in the Figure.

In an edge water drive, the reservoir pressure reaction to production depends on the magnitude and permeability of the aquifer and the rate at which the reservoir is produced. If the reservoir is produced at a small rate, the aquifer is capable to exchange the fluid volumes produced and reservoir pressure remains fairly constant. If the production rates are high, the aquifer is not capable to keep up with removals and reservoir pressure drops. If the rate is then lower to a low level, reservoir pressure will increase as shown in Table 1, 2 and Figure. The rates of production of a particular Edgewater drive reservoir are determined by the size and permeability of its connected aquifer. In a strong Edgewater drive reservoir, the producing gas-oil ratio remains fairly constant, reflecting the stable reservoir pressure show in figure 2 through to figure 3. If the aquifer is not capable to preserve reservoir pressure, the producing gas-oil ratio will rise accordingly [22-24.It was found that the well is optimally located if the well length ( $X_{W D}, Y_{W D}, Z_{W D}$ ) is in the ratio of 12:7:15 respectively. This well position provided the highest recovery and latest breakthrough at all production rates. It was also noted that improved well performance (i.e., greater recovery, later water breakthrough, and lower water cut) is attained at a higher rate than at lower production rates. Water-oil interfaces remain stable and flatting as they move towards the well [25].

\subsection{CONCLUSION}

From the results, it is concluded that for double Edgewater drive, the horizontal well should be located relatively close to the original water-oil interface to achieve a higher recovery and later water and gas breakthrough. However, as the well gets closer to the original water-oil interface, the well's performance deteriorates; therefore, there is an optimum location for the well. Based on the present results, the well should be located at a position such that the ratio of the lengths $\left(X_{w D}, Y_{w D}\right.$, $\left.Z_{w D}\right)$ should be 12:7:15 respectively. It is also concluded that the well should be produced at a higher rate rather than lower rates as long as no water fingers are formed.

\section{NOMENCLATURE}

$\mathrm{P}_{\mathrm{D}}{ }^{1}$ or $\mathrm{P}_{\mathrm{D}}^{\prime}=$ Dimensionless Pressure derivative

$P_{D}=$ Dimensionless Pressure

$h_{D}=$ Dimensionless height

$\mathrm{X}_{\mathrm{D}}=$ arbitrary dimensionless distance along the $\mathrm{x}-$ axis

$Y_{D}=$ arbitrary dimensionless distance along the $y$ axis

$Z_{D}=$ arbitrary dimensionless distance along the $z$-axis

$Z W_{D}=$ Well coordinate in $z$-direction

$Y_{w D}=$ Well coordinate in $y$-direction

$\mathrm{Y}_{\mathrm{wD}}=$ Well coordinate in $y$-direction

$Y_{w D}=$ Well coordinate in y-direction

$\mathrm{Y}_{\mathrm{eD}}=$ External dimensionless distance along $y$-axis

$\mathrm{X}_{\mathrm{wD}}=$ Well coordinate in $\mathrm{x}$-direction

$T_{D}=$ Dimensionless time

\section{ACKNOWLEDGMENTS}

I wish to acknowledge the moral, academic and technical support of my wife, Dorah, and children, as well as Prof Ubeku, Dean of the Faculty of Engineering, Delta State University.

\section{REFERENCES}

[1] Dikken, B.J. JPT 11:1426, 1990.

[2] Giger, F.M. SPE Reservoir Engineering , 4, pp.409-416, 1989.

[3] Ozkan, E. and R. Raghavan, "Performance of Horizontal Wells Subject to Bottom Water Drive," SPE Paper 18545, presented at the SPE Eastern Regional Meeting, C h a r l e s t o n, West Virginia, Nov.2-4, 1988, pp. $375-383$, 1990.

[4] Kuchuk, F.J., Goode, P.A., Brice, B.W., Sherrard, D.W. and Thambynayagam, R.K.M. "Pressure Transient Analysis and Inflow Performance for Horizontal Wells" SPE 63rd Annual Technical Conference and Exhibition. Houston, Texas. SPE 18300, 1989.

[5] Babu, D.K. and Odeh, A.S. "Productivity of a horizontal well", SPE Reservoir Engineering 4, pp. 417, 1989.

[6] Chaperon, I. "Theoretical Study of Coning Toward Horizontal and Vertical Wells in Anisotropic Formations: Subcritical and Critical Rates" 61st SPE Annual Technical Conference and Exhibition, New Orleans, Louisiana. SPE 15377, 1986.

[7] Karcher, B.J., Giger, F.M. and Combe, J. "Some Practical Formulas to Predict Horizontal Well Behavior", SPE 61st Annual Technical 
Conference and Exhibition, New Orleans, Louisiana, SPE 15430, 1986.

[8] Joshi, S.D. Horizontal Well Technology. PennWell Publishing Company: Tulsa, Oklahoma, 78, 1991.

[9] Yang, W. and Wattenberger, R.A. "Water Coning Calculation for Vertical and Horizontal Wells" SPE 66th Annual Technical Conference and Exhibition, Dallas, Texas. SPE Paper \#22931, 1991.

[10] Ozkan, E. and Raghavan, R. SPE Regional Meeting Charleston, West Virginia. SPE 18545, 1988.

[11] Papatzacos, P., Herring, T.U., Martinsen, R. and Skjaeveland, S.M." Cone Breakthrough Time for Horizontal Wells" SPE 64th Annual Technical Conference and Exhibition, San Antonio, Texas. SPE 19822, 1989.

[12] Zhou, D.Y., Jiang, T. W., \& Feng, J. L. "Water flooding performance and pattern in Horizontal well with a bottom water reservoir". Acta Petrolei Sinica, 25(6), pp.73-77, 2004.

[13] Liu, H. Z., Li, L. C., \& Wu, J." Experimental study on the rule of horizontal well water breakthrough in the bottom water reservoir". Journal of Petrochemical Universities, 25(1), pp.57- 60, 2012.

[14] Peng, X. D. "The study on water flooding characteristics and corresponding development with Bottom water reservoir" (Master Thesis). The Chengdu University of Technology, Chengdu, China, 2012.

[15] Sun G., Zhang J. Lei Y, Wang Y. , Chang H., Zhai S., "Numerical Simulation Study for Water Breakthrough Law of Horizontal" 2016.

[16] Arslan O., Wojtanowicz A.K., Kumar A., White C.D., "Early water Production and Bypassed Oil in Edge Water drive Reservoirs" Canadian International Petroleum Conference, 8-10 June,Calgary, Alberta,2004.
[17] Eiroboyi I; Wilkie, SI (2017). "Comparative Evaluation of Pressure Distribution between Horizontal and Vertical Wells in a Reservoir (Edge Water Drive)", Nigerian Journal of Technology (NIJOTECH) Vol. 36, No.2, pp.457 - 460, 2017.

[18] Oloro J.O and Adewole E. S., (2019) Derivation of Pressure Distribution Models for Horizontal Well Using Source Function, J. Appl. Sci. Environ. Manage. Vol. 23 (4), pp.575- 583, 2019.

[19]Gringarten, AC; Ramey, HJ "The Use of Source and Green's Functions in Solving UnsteadyFlow Problems in Reservoirs," SPEJ, pp.255 285, 1973.

[20] Ogunsanya, B.O; Oetama, T.P.; Heinze, J.F."A Physically Consistent Model for describing the Transient Pressure Behavior of Horizontal drain holes", Canadian SPE 2005-071 presented at the 6th Canadian International Petroleum Conference, Calgary, Alberta, pp.7-9 June 2005.

[21] Anthony O. B. "Detection of Water Encroachment into a Marginal Field Oil Reservoir For ultimate Recovery", SPE Nigeria Annual International Conference and Exhibition,4-6, 2015.

[22] Dake, L. P. Fundamentals of Reservoir Engineering: The Netherlands, Elsevier Science Publishers, pp.79-102, 1978.

[23] Ahmed, T.P. Advanced Reservoir Engineering. Oxford, UK: Elsevier Inc., 2005.

[24] Yogesh, K. S.; Ezeddin S.;Hussameldin, I. Abdulsalam, $A$ World Journal of Engineering and Technology, 2, 2331, 2014.

[25] Mohamed A. Aggour and Irfan Sami Khan,"Hele-Shaw Model Study of Horizontal Well Performance in Reservoir with Gas Cap and Bottom Water Drive", Petroleum Science and Technology, 19:5-6, pp.661-672, 2007. 